\title{
Using a Discrete Choice Experiment to Elicit the Demand for a Nutritious Food: Willingness-to-Pay for Orange Maize in Rural Zambia
}

\author{
J. V. Meenakshi \\ Email:meena@econdse.org \\ Department of Economics, Delhi School of Economics \\ A. Banerji \\ Email: a.banerji@econdse.org \\ Department of Economics, Delhi School of Economics \\ Victor Manyong \\ International Institute of Tropical Agriculture \\ Keith Tomlins \\ Natural Resources Institute, University of Greenwich \\ Nitya Mittal \\ Department of Economics, Delhi School of Economics \\ Priscilla Hamukwala \\ University of Zambia
}

\section{Working Paper No. 186}

Centre for Development Economics

Department of Economics, Delhi School of Economics 


\title{
Using a Discrete Choice Experiment to Elicit the Demand for a Nutritious Food: Willingness-to-Pay for Orange Maize in Rural Zambia
}

\author{
J.V. Meenakshi ${ }^{1}$, A. Banerji ${ }^{1}$, Victor Manyong ${ }^{2}$, Keith Tomlins $^{3}$, Nitya Mittal ${ }^{1}$, \\ and Priscilla Hamukwala ${ }^{4}$
}

Acknowledgements: We are indebted to several people for the successful completion of this research: Brian Chisanga, Cornelius Kalonga, Dominic Mambo, and Likando Muyatwa and the team of enumerators who worked hard to successfully meet the rigorous demands of the survey schedule and painstakingly undertook the subsequent data entry. Shyamal Chowdhury provided helpful input during the entire course of the study. We are also grateful to a referee for suggestions that have substantially improved the paper. This research was funded by HarvestPlus. Any errors are those of the authors. Catherine Mungoma, then of ZARI arranged to have the prototype varieties of orange maize grown out, while Rhodah Zulu of NISIR oversaw the food science aspects of the study, including the milling of the maize to correspond to rural practices, the consistent cooking of nshima and taste testing. Rosina Mbewe wrote the radio message.

\footnotetext{
${ }^{1}$ Delhi School of Economics, University of Delhi

${ }^{2}$ International Institute of Tropical Agriculture

${ }^{3}$ Natural Resources Institute, University of Greenwich

${ }^{4}$ University of Zambia
} 


\section{Table of Contents}

ABSTRACT

I. MICRONUTRIENT MALNUTRITION AND BIOFORTIFIED ORANGE MAIZE IN ZAMBIA .................... 3

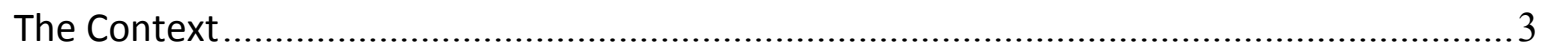

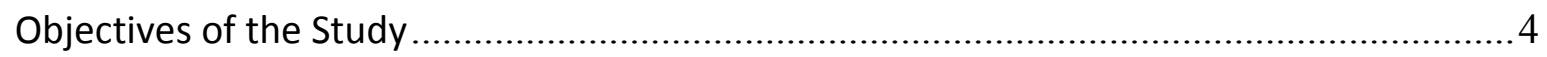

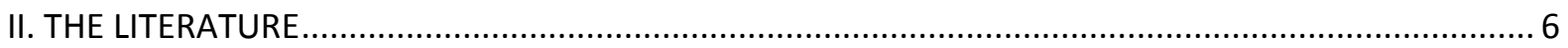

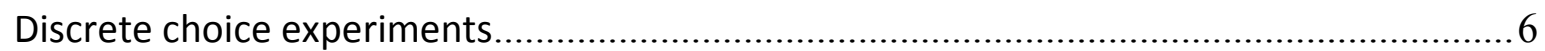

Orange and Yellow Maize in Sub-Saharan Africa............................................................ 7

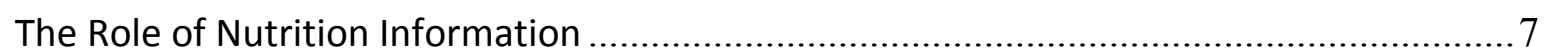

Novelty Value versus Product Experience: Comparing Central-Location Testing with

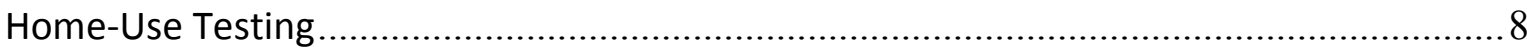

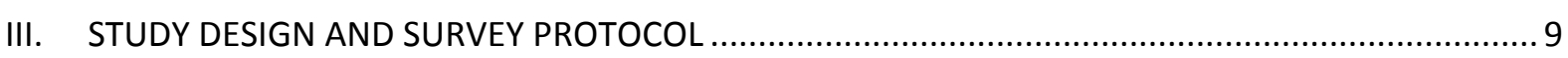

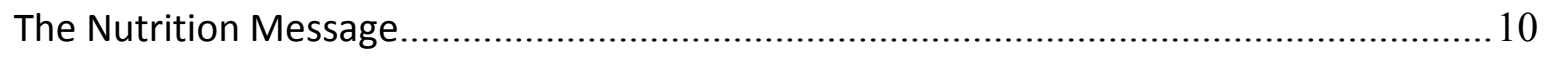

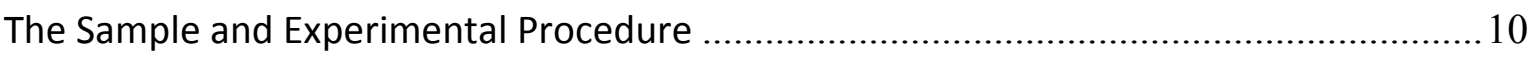

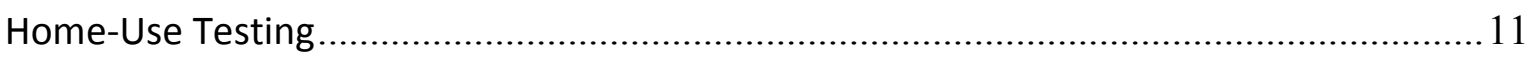

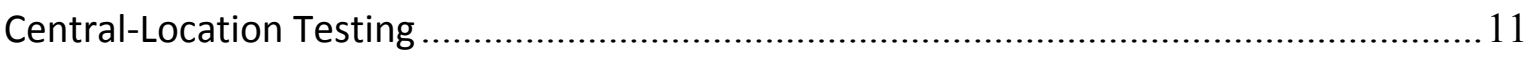

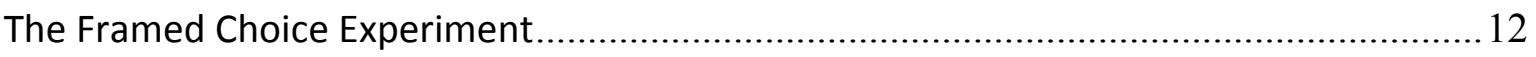

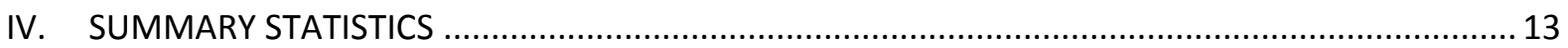

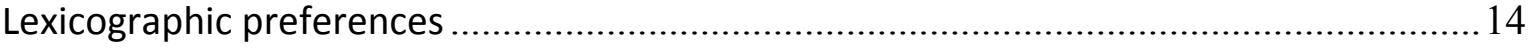

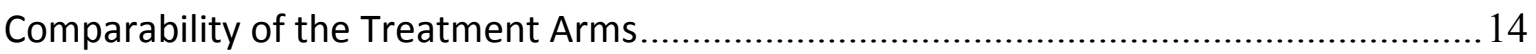

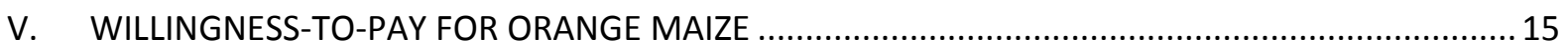

The Conditional Logit and Random Parameters Logit Specifications ................................. 15

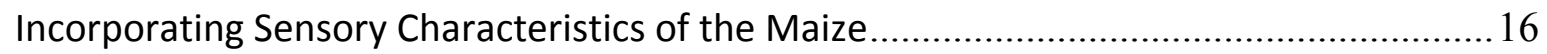

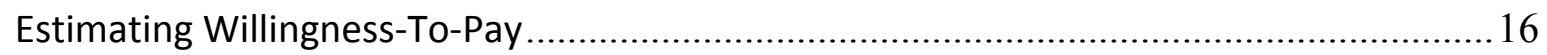

The Premium for Orange Maize with and without Information ...................................... 17

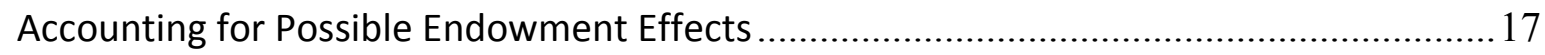

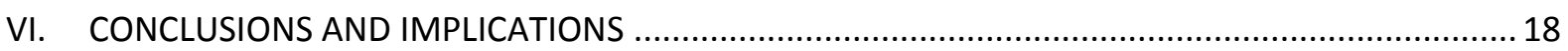

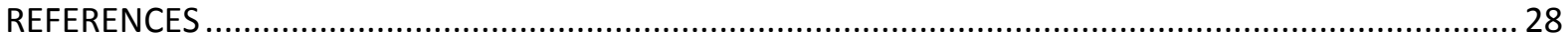




\title{
Using a Discrete Choice Experiment to Elicit the Demand for a Nutritious Food: Willingness-to-Pay for Orange Maize in Rural Zambia
}

\author{
J. V. Meenakshi, A. Banerji, Victor Manyong, Keith Tomlins, Nitya Mittal \\ and Priscilla Hamukwala
}

\begin{abstract}
Using a discrete choice experiment, this paper estimates the willingness to pay for biofortified orange maize in rural Zambia. The study design has five treatment arms, which enable an analysis of the impact of nutrition information, comparing the use of simulated radio versus community leaders in transmitting the nutrition message, on willingness to pay, and to account for possible novelty effects in the magnitude of premiums or discounts. The estimation strategy also takes into account lexicographic preferences of a subset of our respondents. The results suggest that (a) orange maize is well liked and can compete with white maize in the absence of a nutrition campaign, (b) there is a premium for orange maize with nutrition information, and (c) the mode of nutritional-message dissemination does not have a large impact on consumer acceptance, and (d) novelty effects do not translate into higher willingness to pay for orange maize.
\end{abstract}

\section{MICRONUTRIENT MALNUTRITION AND BIOFORTIFIED ORANGE MAIZE IN ZAMBIA}

\section{The Context}

Micronutrient malnutrition is widely recognized as a public health problem in both lowincome and middle-income countries. The Lancet, in a special volume dedicated to maternal and child nutrition, highlighted the role of micronutrient malnutrition in achieving reductions in under-five child mortality (p.2), a two-thirds reduction in which is a millennium development goal. Vitamin A deficiency, in particular, accounts for $6 \%$ of all deaths of children under five years of age, and $5 \%$ of the total disease burden of children in this age group, as measured by Disability-Adjusted Life Years metric. This includes 350,000 children who become blind each year due to Vitamin A deficiency (Black et al, 2008). As in much of sub-Saharan Africa, Zambia has a high prevalence of vitamin A deficiency: more than half of preschool children in Zambia are at risk (Micronutrient Initiative, 2009).

Biofortification is a new public health intervention that seeks to improve the micronutrient content of staple foods consumed by the majority of poor people using conventional plantbreeding techniques in order to make a measurable impact on the magnitude of micronutrient malnutrition. Ranked fifth in interventions by the Copenhagen Consensus Panel in 2008, biofortification explicitly recognizes that while "the causes of vitamin and mineral deficiencies are multiple and interconnected...at the most basic level, the problem is related to diet." (p.iii. Micronutrient Initiative 2009). Recently, plant breeders have developed biofortified varieties of maize that contain higher concentrations of betacarotene (provitamin A) and are therefore orange in color. In this paper, maize that contains significant amounts of beta-carotene is referred to as "orange maize" to distinguish it from yellow maize (which contains levels of carotenoids that are too low to significantly contribute to human health) and white maize (which has no carotenoids). 
Since maize is a staple food in Zambia, as in much of Sub-Saharan Africa, the successful introduction of biofortified provitamin A maize could have a significant impact on reducing the prevalence of vitamin A deficiency in Zambia and elsewhere in Sub-Saharan Africa, where it is a major public health concern. For example the provitamin A content of the orange maize flour ranged from 3.3 to 4.9 micrograms per gram (Tanumihardjo). With a 400 gram per day consumption of maize (common in rural Zambia), and $60 \%$ retention of provitamin A, a 5 micrograms per gram content would translate into an additional intake of 100 micrograms per day of vitamin A, or about 20 percent of the estimated average requirement for an adult (non pregnant non lacatating) woman.

However, the success of such biofortified maize depends on whether it is accepted and consumed by the target populations. It is this question that this paper attempts to address, by eliciting consumers' willingness to pay for this healthy maize, under various scenarios.

Consumer acceptance may pose a particular problem with a product such as maize because in the past yellow varieties have typically not found consumer acceptance. In large part, this is because such varieties are believed to have inferior taste-yellow maize was bred primarily for cattle feed. In addition, yellow maize is perceived as "drought" food and associated with bad times because it was frequently distributed as food aid (Muzhingi et al. 2008). If this negative perception carries over to orange maize, there is reason to be skeptical that biofortified maize will find enough of a niche in Sub-Saharan Africa to be able to make an appreciable difference in micronutrient intakes among target populations.

However, there are several reasons to challenge this perception. First, biofortified maize is likely to be agronomically superior to those presently cultivated; farmers have reported being willing to switch to yellow maize if it were pest-resistant, drought-resistant, and earlymaturing. Second, plant breeders and nutritionists have determined that biofortified maize is likely to be orange and, as such, may avoid the negative perceptions associated with yellow maize. Third, in an account of the introduction of maize into the African continent, McCann (2005) notes that traditional maize varieties were typically colored and devotes an entire chapter to its transformation, titled "How Africa's Maize Turned White." There are also reasons to believe that market restrictions may have more to do with the popularity of white maize than consumer preferences per se (see literature cited by Muzhingi et al. 2008).

\section{Objectives of the Study}

The present study analyzes consumer acceptance of biofortified maize by quantifying consumers' willingness to pay for it in rural Zambia since it is in these areas that biofortified staples will be first introduced. ${ }^{1}$ It attempts to quantify the magnitude of price discounts, if any, that may be associated with orange maize relative to white and yellow maize varieties.

Behavior change communication is essential to any successful nutrition intervention and can play a significant role in driving consumer acceptance. There are several means of effecting behavior change communication, each of which has different cost implications. Radio messages are relatively cheap and can reach a broad audience. At the other end of the cost

\footnotetext{
${ }^{1}$ We do not focus on the agronomic characteristics of the maize seed, as the expectation is that the orange maize will be equivalent, if not superior, to varieties presently cultivated in this respect.
} 
spectrum, using community leaders to convey nutrition information can be extremely expensive. This paper tries to assess how information and the platform used to communicate it influence consumer preferences and their ranking of white, yellow, and orange types of maize.

Another challenge to analyzing consumer acceptance is accounting for product experience. Behavior during first-time purchases, where consumers may wish to try out a new product and therefore may be willing to pay more for it, can be very different than behavior during repeat purchases. This is likely to be the case for maize that is so visibly different from that already available in the market. This paper attempts to account for product experience by comparing behavior in two different settings: at home (where consumers try the product for a few days at home) and in a central location (where consumers are exposed to the new maize only once). Home-use testing surveys are considerably more expensive to undertake than central-location testing surveys.

The paper thus has three principal objectives:

1. To elicit the willingness to pay (henceforth WTP) for orange maize and quantify the magnitude of its premium/discount relative to white maize in the absence of any information on its nutritive value;

2. To examine the impact of nutrition education on the willingness to pay for orange maize, and, in particular, to compare the impact of nutrition education delivered through either radio messages or community leaders; and

3. To examine whether novelty effects significantly influence premiums by comparing willingness to pay as elicited in a home-use setting (where consumers have more time to get used to a product) with that elicited from a central-location setting (which has a short exposure time).

The paper uses a discrete choice experiment using a fractional factorial design as the framework of analysis. While the application of this approach is detailed subsequently in the paper, we highlight some noteworthy aspects;

- This paper represents one of the few applications of this framework to the analysis of public health issues in general and in rural Africa in particular.

- It uses prototypes of the actual product, rather than hypothetical experiments to elicit willingness to pay.

- The study uses expertise from food scientists who use sensory evaluation methods to assess preference rankings; this study is perhaps one of the few to then explicitly incorporate these rankings in the econometric analysis.

- The estimation method accounts for differences in preferences exhibited by a subset of our sample, some of whom appear to have lexicographic orderings.

A survey of nearly 500 respondents in two provinces of rural Zambia forms the basis of analysis. The survey has five treatment arms corresponding to the objectives outlined above.

The paper is organized as follows: Section II briefly reviews the literature on the use of discrete choice experiments to assess prices for goods (that may not yet be on the market), as a function of their characteristics; the literature on the role of information and product 
experience on consumer acceptance; and the limited studies on colored maize in Africa. Section III then sets out the survey design and experimental procedure. Section IV presents summary statistics, while Section $V$ investigates whether there is a premium for orange maize, the magnitude of this health premium, and how this is influenced by the absence or presence of information on its nutritive value. Section VI summarizes the results and draws implications for the successful introduction of biofortified maize in rural Zambia.

\section{THE LITERATURE}

\section{Discrete choice experiments}

Discrete choice experiments have been increasingly used to determing consumers' willingess to pay for non-market and new goods. As Lusk and Schroeder (2004) note, choice experiments are increasingly favored over contingent valuation techniques to elicit preferences for such products.

Discrete choice experiments can be conducted and interpreted using McFadden's (1974) random utility model. Given a set of alternatives-orange, white, or yellow maize in the present context-each priced differently, respondents make a choice of which of the three they would prefer to purchase based on the utility they derive from the consumption of the product. That is, the utility $U_{\mathrm{ij}}$ that consumer $i$ derives from product $j$ is postulated to have a systematic component $\left(\mathrm{V}_{\mathrm{ij}}\right)$ and a random component $\left(\mathrm{e}_{\mathrm{ij}}\right)$.

$\mathrm{U}_{\mathrm{ij}}=\mathrm{V}_{\mathrm{ij}}+\mathrm{e}_{\mathrm{ij}} ; \mathrm{V}_{\mathrm{ij}}=\mathrm{X}_{\mathrm{ij}} \beta$

The systematic component $V_{i j}$ is a function of observable characteristics $\left(X_{i j}\right)$ of the alternatives (such as price) and those of the respondent (such as gender, income, and age). The consumer chooses alternative $j$ over alternative $k$ if $\mathrm{U}_{\mathrm{ij}}>\mathrm{U}_{\mathrm{ik}} \forall \mathrm{k} \neq \mathrm{j}$. A suitable parameterization of $V_{i j}$ yields estimates of WTP as described in Section $V$ below.

A fractional factorial design may be used to present respondents with trade-offs between the products' attributes and their prices. A good description of the design and construction of choice experiments is contained in Hensher et al. (2005a) while Louviere et al. (2000) and Train (2009) are good introductions to the theory of discrete choice experiments and contain applications as well and some references to the extensive literature applying this basic framework, especially in the context of transportation, and environmental goods (see for example Das et al, 2009; 2008).

The quantification of the relative discounts or premiums for products that are not yet on the market-as is the case with the orange maize studied here-poses particular challenges. Typically, carefully-constructed hypothetical scenarios are used to elicit willingness to pay. In less frequent cases, the actual product or its prototype is used.

Over the years, a consensus has emerged that results from the use of hypothetical scenarios tend to have an upward bias in that consumers often overstate their willingness to pay for a commodity or service. (See for example, Jaeger 2005 and Lusk and Schroeder 2006.) This is 
corroborated by a more recent study on maize in Kenya by de Groote and Kimenju (2008) that finds that consumers have no incentive not to overstate the price they are willing to pay in a hypothetical scenario.

This paper therefore is more in the spirit of Lusk and Schroeder (2006) and Alfines et al. (2006) who not only focus on food, but use the real product to elicit WTP. As noted later, the prototypes of the biofortified orange maize were grown out in country to use in the study. We also draw on Train (1998), Hensher et al (2005b) and Campbell et al. (2006) to account for the not-insubstantial proportion of respondents in our sample who exhibited lexicographic preferences.

\section{Orange and Yellow Maize in Sub-Saharan Africa}

There have been several studies on the consumer acceptance of yellow maize (which is not typically high in beta-carotene), although many of them tend to have an urban focus. A comparison between yellow and white maize varieties is facilitated by the fact that both products are available in the market, so price data can be used to make inferences about the magnitude of discounts. For example, the existence of a price premium for white maize in Maputo, Mozambique (at a time of relative abundance in supply of both yellow and white maize) is evidence that white varieties are preferred. In their study, Tschirley and Santos (1995) found that white maize is preferred to yellow when the two are sold at equal prices. However, a price discount of only 14 percent on yellow grain was found to be sufficient to cause a quarter of respondents - typically those with lower incomes on average-to switch to yellow maize. At discounts of up to 43 percent, nearly three-quarters of consumers would shift to yellow maize.

Another analysis using experimental auctions to assess willingness to pay and focusing on yellow (but commercially fortified) maize flour in Nairobi suggests that a discount of 33 percent would be necessary for consumers to accept yellow maize, although poorer consumers are more likely to switch for a given discount (De Groote and Kimenju 2008).

The literature on comparing white with orange-rather than yellow-maize is limited. One exception is the study by Stevens and Winter-Nelson (2008), which includes white, yellow, and orange (imported from the United States) varieties of maize. These were cooked as nshima (a stiff porridge made from maize flour) and tested in two markets in and near Maputo. Researchers provided all participants with a bag of white maize and made an announcement about the nutritional value of orange maize. They then assessed whether participants were willing to trade their bag for one containing either a fraction or a multiple of the amount of orange maize. Their results suggest that orange maize meal is as preferred as white and that no price discounts are likely to be necessary to promote its consumption. In addition, families with young children and those that did not consume diets rich in animal products were more likely to accept orange maize. This paper did not, however, assess what would happen in the absence of information on the nutritive value of orange maize.

\section{The Role of Nutrition Information}

Behavior change communication or nutrition campaigns are conducted using several methods, including mass media, local theater, and endorsements from public figures, 
community-level actors, or organizations. Each of these media vary significantly in impact and in cost implications. This paper attempts to examine the impact of nutritional information conveyed through community leaders and radio messages.

In a developed-country context, health information is typically conveyed through the use of written labels, and the literature suggests that premiums for health labeling can be significant (Kinnucan et al. 1997). The use of written labeling is not practical in the context of rural Zambia, given low levels of literacy, costs of labeling, and maize being sold in open sacks. By using community leaders and radio messages for conveying health information, the context is more realistic than using enumerators to read out the nutrition message.

The use of community leaders and interpersonal contact to deliver a message is the most effective method (Zimicki 1997). It is believed that community-level actors are likely to be the most effective agents of change with the greatest impact on outcomes since they occupy positions of trust and respect within the community. Examples could include extension workers, teachers and health workers. However, outside of a pilot setting, mobilizing community leaders on a wide scale is difficult, and the monitoring costs of ensuring that messages are not diluted or distorted are extremely high.

At the other end of the spectrum are radio messages, which enable a wide reach with relatively low investment and high degree of control over the content of the message (although there is less control over who will hear the message). However, radio messages represent an anonymous voice that consumers may not trust, and therefore they may not be effective. It is estimated that there are 1.9 million radios in Zambia (Taylor 2006), of which around 30 percent are in rural areas (Zimicki 1997). As shown later, our survey indicates that a decade later, the percentage of households possessing a radio in rural areas is much higher.

We attempt to quantify the magnitude of this differential impact by randomly allocating respondents/communities to arms that (a) receive no information (termed "control"), (b) receive information from (simulated) radio messages, or (c) receive information from community leaders.

\section{Novelty Value versus Product Experience: Comparing Central-Location Testing with Home- Use Testing}

Test marketing of new products typically takes places in a marketplace or a similar community venue, in a format referred to in food science literature as "central location testing" (CLT). One potential drawback of using CLT to elicit willingness to pay for a new product is that estimates may be influenced by its novelty value, since consumers have only a short period of time to evaluate a product (typically 30 minutes). Consumers may be willing to pay a premium to try out a new product for the first time, so that the estimated willingness to pay may not reflect the product's intrinsic value. As Stevens and WinterNelson (2008) note in their study of biofortified orange maize in Mozambique, "measurement of acceptance may reflect an attraction to novelty than true acceptability of the product". The premise then is that with time and experience with the product, repeat purchases may well reflect declining premiums. 
For this reason, "home-use testing" (HUT) is also conducted, where the new product is tried in home situations for a few days, and consumers are asked subsequently to characterize it. Clearly, the degree of researchers' control over the experiment is lower in HUT because households are free to cook or use the product in any manner, so that it is possible that sensory scores vary across respondents not necessarily because of intrinsic differences on how the product is perceived but on how the product was processed and consumed. Nevertheless, to the extent that the in-home testing more closely mimics actual product use, it may be considered the gold standard for conducting consumer acceptance studies. However, the costs of administering home-use testing are orders of magnitude greater than those associated with central-location testing; the question is whether these additional costs are justified.

Comparisons of the effectiveness of CLT and HUT methods with respect to acceptance (Boutrolle et al. 2005, Meilgaard et al. 2007) suggest that both gave similar overall results, but the CLT results were more robust and less variable. These methods have thus far not been compared in a developing country and with rural consumers; willingness-to-pay studies that use real products have almost invariably been conducted in a central location setting (see for example Lusk and Shroeder 2004, Alfines et al. 2006).

This study uses both central-location testing and home-use testing to assess consumers' willingness to pay (WTP) for orange maize, relative to other varieties. For reasons outlined later, a strict comparison of the estimated WTP from HUT and CLT is not possible; however, the inclusion of both treatment arms permits a check on the robustness of the main findings of the study.

\section{STUDY DESIGN AND SURVEY PROTOCOL}

The study has five treatment arms, summarized in Table 1 along with each arm's sample size. In each case, consumers were asked to taste cooked samples of nshima and make purchase decisions on the corresponding maize grain. Two of these treatments correspond to one-time use of orange maize (CLT) while three consider the impact of product experience (HUT).

The role of nutrition information is assessed within both the CLT and HUT settings. Since it is not possible to replicate the use of community leaders to impart nutrition information in a central location setting, the CLT arm of the design considers only the impact of the provision of nutrition information through simulated radio messages.

Treatments 1 and 4 provide estimates of the willingness to pay for the three maize varieties in the absence of any information on the nutritive value of the orange maize in the HUT and CLT settings respectively. These values reflect how well orange maize is likely to do in comparison to the familiar white varieties in the absence of any nutrition campaign. A comparison of treatments 1 and 2 and of 4 and 5 provides an estimate of the impact of nutrition information transmitted through radio on valuations in each of the HUT and CLT settings respectively, and may be used to evaluate whether premiums vary with and without novelty value. Finally, a comparison of treatments 1 and 2 and 1 and 3 yields 
insights on whether community leaders are more effective in improving consumer acceptance compared with the more impersonal radio message.

\section{The Nutrition Message}

Information on the potential health benefits from consuming orange maize was developed by nutritionists working on public health campaigns and contained the following points:

- A new type of maize that is orange (and not yellow) in color has been developed by researchers that is healthier than white maize.

- The new orange-colored maize contains vitamin A and can be used in the same way as traditional maize.

- Vitamin A is important for health, especially for children, because it helps to prevent infectious diseases, to improve growth, and to contribute toward good vision. A deficiency of vitamin A can contribute to higher mortality rates. Foods that commonly contain vitamin A include dairy products, liver, egg yolks, and fruits and vegetables, especially those that are deep orange or dark green in color.

The Zambia National Broadcasting Corporation then wrote and produced a five-minute program in English in a format that would typically be used in such promotions. This was translated and recorded in the study area's three local languages-Bemba, Lenje, and Tonga. Since orange maize varieties are yet to be released, the radio message could obviously not be broadcast nor could the project ensure that only the selected households heard the message. Therefore, the message was recorded on audio tapes and MP3 players that were used in the survey for treatment arms 2 and 5 in Table 1.

Camp officers-who are village-level functionaries-were recruited for training and sensitization at the respective district headquarters, since they are the natural entry point for introducing an agricultural technology. Enumerators explained and reviewed the nutrition message and answered questions on what could and could not be said about the new orange maize. They were asked to convey these messages to their respective communities before the survey and to reiterate them during the survey. An information sheet was also made available to guide the camp officers.

\section{The Sample and Experimental Procedure}

The research was assessed and approved by the Research Ethics Committees of the University of Zambia and the University of Greenwich. Written consent was sought for adults participating in this study. Written and parental/guardian consent was obtained for children under the age of 18 . The trained enumerators informed participants about the study and explained that their participation was entirely voluntary, which meant they could stop the interview at any point and that their responses would be anonymous.

The study made use of prototype high beta-carotene orange maize that was grown out specifically for this study by the Zambia Agricultural Research Institute. In addition, traditional white and yellow varieties were purchased locally. These three types of maize grain were then milled in a hammer mill commonly used in rural areas (rather than in commercial mills that mill to a different texture and cater primarily to urban markets). The 
National Institute for Scientific and Industrial Research in Lusaka undertook the milling, bagging, and preparation.

The survey was conducted in the Central and Southern Provinces of Zambia, which were selected because they have the highest production and consumption of maize. These provinces also had a relatively high percent of their populations in poverty. In each province, a listing of districts was made, and one district was randomly selected. For logistical reasons, a second district was then chosen as the one closest to the randomly selected one. Thus, Chibombo and Kapiri Mposhi districts in the Central Province and Choma and Kalomo districts in the Southern Province were selected (depicted in Figure 1).

\section{Home-Use Testing}

To select participating households for these districts, a listing of blocks and camps (villages) was obtained. Three blocks were randomly selected from each district, and eight camps were randomly drawn from within these three blocks. In the selected camps, existing census data (known as "farmers' register") was obtained. The census data categorize farmers as "small-scale," "medium-scale," and "commercial." A random sample of 10 households was drawn from the "small-scale" list in each selected camp. In other words, the sample has no representation of either medium-scale or commercial producers, so that it best approximates the target population for biofortified crops. Where the farmers' register was not available, a census was undertaken and then a random sample drawn. A replacement sample was also selected randomly in the event that the selected household was either not to be found or did not want to participate in the study. Two villages were dropped because they were relatively inaccessible, and the rest were randomly allocated to the treatment arms:

Group 1: $\quad$ Control group (10 camps)

Group 2: $\quad$ Group receiving nutrition information from camp officers (10 camps)

Group 3: Group receiving nutrition information through simulated (recorded) radio messages (10 camps)

In each camp, a list of ten households was identified as described above for a total of 300 households; the realized sample size was somewhat different, as noted in Table 1, because, in one Group 2 village, the camp officer did not hold any meetings nor did he convey the nutrition message to his village, even though he had participated in the training. For this reason, there were only nine communities that received nutrition information through their leaders. Although data were collected in this tenth camp, it is not used in the analysis that follows. We also decided against allocating it to the control group of villages. The total number of households canvassed under HUT is therefore 279.

\section{Central-Location Testing}

For the central-location testing, a village was first selected in each of the two provinces. In each village, the community leader visited adjacent camps to invite villagers to participate in the survey at a pre-specified location, typically the local market or agricultural training center. As participants came to the location, they were randomly assigned to one of the two treatments. The first treatment corresponded to the control group, and, in the second, the nutrition message was conveyed through the simulated radio using MP3 players. We used 
spatial separation to ensure that there was no contamination of the control group with messages diffusing from participants who had already participated in the survey. More than 100 consumers were canvassed at each of the two locations, for a total sample size of 208.

\section{Sensory evaluation of the attributes of orange, yellow and white maizes}

In collaboration with food scientists from the National Institute of Scientific and Industrial Research, four attributes of maize that are likely to influence its acceptance were determined: taste, appearance, aroma, and texture. In addition, an overall acceptability attribute was also included. After tasting the three varieites, consumers were asked to score each of these attributes using a five-point hedonic box scale, which ranged from "dislike extremely" to "like extremely."

In the central-location testing, consumers were provided with cooked samples of the three types of nshima, presented in random order on white plates with water to cleanse the palate between samples. After tasting each sample, the respondents were asked to score their preferences on the nshima's sensory attributes. The respondents in the nutritioninformation treatment arm heard the radio message before they tasted the three types of nshima.

Respondents in home-use testing were provided 2 kilos each of the three types of maize flour-white, yellow, and orange-sequentially and in random order, to control for possible order-effects in preference elicitation. ${ }^{2}$ The flour was not identified by variety; instead, a three-digit random number was assigned to each of the three varieties. Visually, of course, the three types of maize are distinct. Respondents had two days to try each type of maize, using their usual household recipes. After handing out the first sample, enumerators would return two days later and ask about sensory evaluation of the various attributes of the first sample, while handing over the second sample. The process was repeated every two days until the fourth and final visit.

\section{The Framed Choice Experiment}

After scoring the three maizes for their sensory characterisitics, respondents were asked about their willingness to pay, and a brief questionnaire eliciting demographic information and other socioeconomic indicators was administered. Most of the respondents who participated in the choice experiment-nearly three quarters-reported that they (and not some other member of the family) were responsible for making the decision to purchase maize within the family. The willingness to pay questions referred to the maize grain, since it is grain that is typically purchased and not the flour. The correspondence between the flour/nshima and the grain was obvious by color but also by the use of the same random number to label the grain and flour/nshima.

As noted earlier, a framed choice experiment using a fractional factorial design was used to elicit willingness to pay. Even though there are concerns over the efficiency of orthogonal designs (Scarpa and Rose, 2008) according to Louviere et al. (2000) these are the most suitable designs that are currently available (see Ferrini and Scarpa, 2007 for a discussion of the issue). In a choice experiment, prices are posted for each of the three types, and the

\footnotetext{
${ }^{2}$ Constraints on the total amount of orange maize available precluded the provision of larger amounts to each household.
} 
respondent indicates which of the alternatives he or she would be willing to purchase. The set of three posted prices is then varied in a series of alternative scenarios, and the respondent makes a decision each time. A fourth alternative of "none of the above" is always available. These are real choices that the respondent makes with real money. Respondents are given a lump sum amount of money as participation fee so that they are not out of pocket as a consequence of buying a product in the experiment. After the respondent has made a decision in each of the sixteen price scenarios, one of the scenarios is picked by a random draw to "bind"; that is, the respondent has to purchase the maize that he or she had indicated as most preferred for this scenario, at the price for which it was offered. In this way, the choice experiment is an incentive-compatible method of eliciting consumer preferences.

To determine the price scenarios, the median prevailing prices for white maize in the study area were first ascertained over the course of a pretest. Prices of the maize were then varied reflecting a range of discounts and premiums-from 30 to 50 percent of the median price. The order of the sixteen price scenarios was scrambled and presented in random order.

Additional information on factors that could condition price and sensory evaluation responses-such as household incomes and assets, household composition, frequency of intakes of maize, attitudes towards maize, demographic structure of the household, and access to sources of information-was also collected. Depending on the treatment arm, a set of questions testing retention of nutrition messages was also posed to consumers.

\section{SUMMARY STATISTICS}

Table 2 presents some summary statistics about maize consumption, cultivation practices, and other characteristics of the sample. As might be expected, virtually the entire sample reported that maize was their primary staple, consumed daily. They also reported that nshima was consumed every day thereby validating the use of nshima in the sensory-testing component of the survey.

Respondents' exposure to markets for maize grain is also substantial: 76 percent of the CLT sample and 52 percent of the HUT sample reported that they had sold maize. Over half the sample reported "own production" as their primary source of maize for consumption; consumption out of own production did not preclude market purchases for consumption.

Nearly half the respondents reported receiving information about maize. The predominant source for information about maize was the public sector extension system for both HUT and CLT respondents, although the proportion for HUT was higher. Between 12 and 16 percent of those who received information on maize did so through nongovernmental organizations.

Exposure to radio is quite widespread in rural Zambia: 57 percent of HUT and 71 percent of CLT respondents reported owning a radio. Public radio stations seem to predominate, although community radio stations are also popular. A third of the respondents reported 
listening to radio after 6 p.m., while another third said that they typically listened to the radio in the mornings, before noon. This suggests that use of radio stations to convey nutrition messages can be quite effective in rural Zambia.

Figure 2 presents the overall acceptance scores for the three different types of maize. In all treatment arms the acceptance of orange maize is comparable, or somewhat higher than that of white maize. Similarly, in all treatment arms, yellow maize has a lower acceptability score than white maize.

\section{Lexicographic preferences}

Given the magnitude of the participation fee, which is equivalent to about US\$0.50 per day-a substantial amount for rural Zambians-one concern in implementing the survey was that consumers would choose to consistently mark "none of the above" as their preferred choice, as this would allow them to keep the entire participation fee without having to make a purchase. This did not happen at all in the survey, however.

Instead, another response was in play-consumers consistently chose only one type of maize in all choice scenarios. A substantial proportion of respondents almost invariably chose orange maize, irrespective of the prices of the three types of maize on offer. This clearly translated into an assurance that they would be able to purchase the orange maize. In our sample, one-fifth of the control group in the central-location testing scenario consistently chose only orange maize, while nearly one-third of those who received nutrition information did the same. Similarly, one-fourth of those in treatment 1 and onethird of those in treatment groups 2 and 3 consistently chose orange maize, irrespective of the prices they faced. A relatively small proportion of consumers-about 4 percent-also systematically chose only white maize, irrespective of the prices they faced.

As indicated in Table 4, for most demographic characteristics, including age and assets, there were no statistically significant differences between those individuals who exhibited lexicographic preferences and those who did not, with one important exception: gender. A significantly higher proportion of the lexicographic individuals were men, as compared to the rest of the sample.

This behavior indicates that for this subset of consumers, the price attribute is irrelevant. This has consequences for the estimation strategy as the inclusion of consumers who exhibited such lexicographic preferences without accounting for their lack of responsiveness to price would result in estimated WTP for orange maize that are likely to be overstated.

\section{Comparability of the Treatment Arms}

As a check on whether the random allocation of treatments to communities was successful, Table 3 provides summary statistics on key observables. Within the HUT and CLT settings, the demographic and socioeconomic characteristics appear not to vary significantly across treatment arms. In other words, more than 90 percent of respondents in the three HUT settings reported farming as the main source of employment, and the differences between the three are not significant. Similarly, nearly 80 percent of respondents in the two CLT settings reported farming as the main source of employment, and the difference between the two treatment arms was also insignificant. This is true for other variables, including the 
average index of assets owned (constructed as a normalized sum of the assets owned by the respondent), the percent of respondents with primary education, and so on.

However, this is not the case across the HUT and CLT groups. On average, respondents in the HUT treatment arms were older (by about five years), more likely to have had a primary education, and cultivated less area but relied more on farming as their main occupation than their CLT counterparts. In part, this is likely a reflection of the different sampling strategies followed in the CLT and HUT settings (outlined above). Therefore, while the randomization exercise appears to have been successful within the HUT and CLT arms in that key demographic variables do not vary across treatments within each, respondents in the CLT arms had a statistically different demographic and socioeconomic profile than those in the HUT arms. The net impact of these differences on estimated willingness-to-pay is hard to predict.

Another factor that vitiates a direct comparison between the HUT and CLT relates to the differential endowments received: HUT consumers received maize flour to try at home, in addition to a participation fee, while CLT respondents received only a participation fee.

However, while the endowment effect may be expected to increase the estimated willingness-to-pay of HUT respondents relative to those in the CLT, there is no reason to expect that this would also affect the magnitude of premiums and discounts of the orange maize relative to white maize.

\section{WILLINGNESS-TO-PAY FOR ORANGE MAIZE}

\section{The Conditional Logit and Random Parameters Logit Specifications}

The basic random utility framework outlined above in Section II can be used to estimate willingness to pay for each of the alternatives. The most commonly used specification is the conditional logit model, where the error term $e_{i j}$ is assumed to follow an extreme value distribution. In this case, the probability $\mathrm{P}_{\mathrm{ij}}$ that the $i$ th consumer chooses the $j$ th alternative (over all possible other alternatives, or $k$ ) is given by:

$$
P_{i j}=P\left(U_{i j}>U_{i k}\right) \forall k \neq j=\frac{\exp \left(V_{i j}\right)}{\sum \exp \left(V_{i k}\right)}
$$

Another more general class of models is the random parameters logit model, also referred to as the mixed logit model, which allows for individual taste variation through random or individual-specific effects and can account for unobserved heterogeneity (Train 1998; Louviere et al. 2000). In this model, one or more of the coefficients $\beta$ are assumed to be random (it is common to assume normal, log-normal, uniform, or triangular distributions for these), while the error term follows the extreme value distribution. In this paper, the parameter corresponding to 'taste' (see the utility specification below) is specified to be random, following a uniform distribution.

Because our sample had a considerable number of respondents consistently choosing orange maize, irrespective of the prices they faced, both the multinomial logit and random 
parameters logit models are estimated following the approach of Campbell et al. (2006) and Hensher et al. (2005) by assuming that for these consumers, the coefficient associated with price is zero. Following the literature, we term these multinomial logit/random parameters logit with lexicographic preferences.

After some experimentation, gender, age and assets were used as individual-level covariates, with an asset index constructed using information on ownership of about 12 distinct assets, using principal components.

\section{Incorporating Sensory Characteristics of the Maize}

In addition to the demographic and price variables, we also included a hedonic covariate capturing the individual's ranking of each maize on its sensory attributes. Since consumer rankings of most of the sensory characteristics were highly correlated, a first principalcomponent weighted average of the five attributes was used in the estimation.

The inclusion of this variable implies that the utility function takes as an argument an individual's taste for the product. This is in some sense similar to industrial organization models of horizontal and vertical differentiation (e.g. d'Aspremont, Gabscewicz and Thisse (1979), Shaked and Sutton (1982)) in which consumers' taste for a product enters the utility function.

\section{Estimating Willingness-To-Pay}

Thus after some experimentation, $\mathrm{V}_{\mathrm{ij}}$ was specified as follows:

$V_{i j}=\beta_{1 j}+\beta_{2 i j}$ Taste $_{i j}+\beta_{3}$ Price $_{j}+\beta_{4}$ Age $_{i} *$ Price $_{j}+\beta_{5 j}$ Gender $_{i}+\beta_{6}$ Asset $_{i} *$ Price $_{j}$

where Taste refers to the hedonic covariate, Price refers to the price of the $j$ th alternative, Gender, Age, and Asset refer to the gender, age, and index of assets accessed by the ith respondent. A higher score for Taste increases utility; also, in the random parameters model, $\beta_{2 i j}$ is randomly distributed in the population, capturing a scenario in which different consumers value Taste differently. The inclusion of color dummies yields insignificant coefficients and is therefore not used in the estimation.

With an explicit parameterization of $\mathrm{V}_{\mathrm{ij}}$, these models may be estimated using maximum likelihood (conditional logit) or simulated maximum likelihood (random parameters logit). The willingness to pay for each variety can then be computed as a function of the estimated parameters.

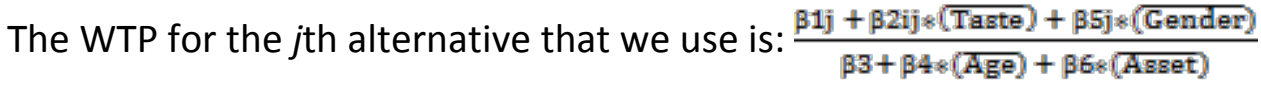

where the variables are evaluated at the sample means. Constructing the average willingness to pay by first estimating the WTP for each respondent and then taking an average across respondents gives estimates that are very close to those defined above.

Table 5 presents the log likelihood values and McFadden's R-squared values for the conditional and random parameters logit models, both in the basic and lexicographic 
variants, for each of the five treatment arms. It is clear that the lexicographic models have significantly higher log likelihood values in each treatment arm but that the random parameter logit models have virtually the same log likelihood values as their conditional logit counterparts; the difference is not large. That is, accounting for lexicographic preferences matters more than the random parameters generalization. The McFadden's Rsquared values are also in an acceptable range, and are higher for the random parameters model. Table 6 presents the estimated coefficients for the random parameters logit model with lexicographic preferences for all five treatment arms. By and large, the estimated coefficients all have the correct signs and are statistically significant.

\section{The Premium for Orange Maize with and without Information}

Table 7 presents the estimated premiums/discounts for yellow and orange varieties relative to white maize for the conditional and random parameters logit models with lexicographic preferences for each of the five treatments, while Table 8 provides the corresponding willingness-to-pay estimates. ${ }^{3}$ The percentage premiums do not vary widely between the two models; we focus, therefore, on the premiums/discounts derived from the random parameters logit models.

It is clear that orange varieties do not suffer any price disadvantage relative to white maize. In the absence of any nutritional information, orange varieties are liked and do not suffer a discount. The difference in willingness to pay between white and orange varieties is insignificant in both CLT and HUT scenarios. With nutrition information from the radio, orange varieties command a premium of 15 percent in the HUT case and 32 percent in the CLT case. Interestingly, while the provision of nutrition information through community leaders also translates into a premium for orange maize of 17 percent, it is not substantially larger than the 15 percent premium from simulated radio. That is, the magnitudes of the premiums for orange maize appear to be the same for both sources of nutrition information.

As expected, yellow maize varieties suffer a discount relative to white maize in all treatment arms, and the difference is statistically significant in nearly all cases. The provision of nutrition information does nothing to alter the discount on yellow varieties. This agrees with prior hypotheses about the acceptability of yellow maize in Zambia and, more importantly, indicates that consumers do not confuse orange for yellow maize.

Respondents in the CLT and HUT arms are not directly comparable, as noted in Section IV. However, it is interesting to note that the broad conclusion of a premium for orange varieties and a discount for yellow varieties holds regardless of whether the CLT or HUT was used. Given the much greater simplicity of the CLT approach, this would argue in favor of using CLT.

\section{Accounting for Possible Endowment Effects}

In addition to the somewhat different demographic profile of respondents in the CLT and HUT arms, a direct comparison between the two sets of treatments is vitiated by the

\footnotetext{
${ }^{3}$ As Poe et al. (1994) have argued, it may be appropriate to use a convolutions approach to test whether the distributions of the estimated willingness to pay vary significantly. We leave this for a future exercise, and focus instead on differences in the mean willingness to pay.
} 
presence of an endowment effect. Respondents in the CLT arms received a participation fee of 2000 Zambian kwachas (ZK), whereas those in the HUT arms received about 6 kilos of maize flour in addition to the ZK 2000 participation fee. Valuing the maize flour at median prices for white maize translates into an endowment for the HUT participants more than five times higher than that of the CLT participants. In addition, those in the HUT treatments who received the radio message obtained, albeit temporarily, a radio-cum-cassette player.

Although the endowment effect does not seem to have been felt on the magnitudes of premiums (for orange) and discounts (for yellow), there are systematic differences in the absolute magnitudes of the willingness-to-pay estimates. A comparison of the willingnessto-pay estimates between treatments 1 and 4 (those given no nutrition information) and between 2 and 5 (those given nutrition information from radio) in Table 8 suggests that, in general, the estimated willingness to pay is higher in the HUT treatment arms. Whether this result is because of the different demographic profile of the two sets of respondents, the higher endowments implied by the design of the HUT, or whether consumers just grew to like orange maize more as they gained experience with it cannot be determined precisely.

The endowment effect merits closer attention. The literature reviewed by Clark (2002) suggests that a "windfall" income, such as that represented by the participation fee, is treated differently by consumers and may result, for example, in a greater marginal propensity to consume-in our case, a higher willingness to pay as a result of receiving the participation fee. Clark's paper suggests that such "house money" effects are not significant, a result disputed by Harrison (2007). Other work on the role of house money includes that of Cherry et al. (2005). Although there appears to be no consensus in the literature on the significance of the endowment, the potential influence of a large endowment effect implicit in the participation fee and maize given to respondents cannot be ruled out.

Therefore, we attempted to account for the role of the endowment effect by estimating a combined model for all five treatment arms. In addition to the other covariates, we included dummy variables for (a) the HUT treatment arms, (b) treatments 2 and 5 that received information through the simulated radio, and (c) treatment 3 that received information through community leaders. The coefficients associated with the HUT dummy are positive and significant (see Table 9), which suggests that, to the extent that the dummy variable captures endowment effects, it significantly influences consumers' willingness to pay. The last column of Table 8 presents the willingness-to-pay estimates from this model as well. While this model does result in lowering the differences in the willingness to pay between the CLT and HUT treatments, the differences are not eliminated. This may be attributed to the impact of product experience or perhaps an experimenter effect. Note also that the coefficient associated with the provision of radio information is significant for orange but insignificant when associated with community leaders. Also, viewed as a restricted version of a more general model where parameters vary across treatments, this combined model does not do as well as the more general model.

\section{CONCLUSIONS AND IMPLICATIONS}

Our results endorse the following main conclusions. 
- Orange maize is likely to be accepted by rural consumers in Zambia.

- Nutrition campaigns translate into improved acceptance and willingness to pay for orange maize.

- There is no appreciable difference in the impact of information received from community leaders versus information received from the radio, which has significant cost implications. This result merits further investigation, but it is possible that the intrinsic nature of the orange maize is driving this result.

- While the results for the home-unit testing are different from the central-location testing in terms of magnitudes and are, strictly speaking, not comparable, speaking qualitatively the results are consistent across both methods.

The primary implication is that there is reason to be confident that any negative connotations associated with yellow maize are unlikely to carry over to orange maize; orange maize carries a premium and no discount even in the absence of nutrition information. On the other hand, the willingness-to-pay estimates clearly indicate a discount for yellow maize relative to white varieties, which is not eliminated with the provision of nutrition information.

Even though magnitudes of premiums vary, since this result is arrived at in both CLT and HUT settings the implication is that the additional cost of conducting a HUT survey could be avoided and the simpler-to-implement central-location testing method should be used in subsequent analyses of consumer acceptance.

An intriguing result relates to the near equivalence of mass media and community-level communication strategies in influencing consumer acceptance. While it is not the intention to posit these as "either-or" strategies, these results suggest that the role of mass media in communicating and reinforcing messages is likely to be significant. Retention of nutrition messages, at least in the short term, from radio messages appears to have been the same as retention from listening to community leaders. The fact that more than 60 percent of the sample reported owning a radio suggests that the impact of this medium of communication is likely to be significant.

Given equal or superior agronomic performance of the orange maize varieties, they may attract a premium in the market. Small-scale producers in rural Zambia (who constituted our sample) have considerable market exposure, both as sellers of maize and buyers of maize. They also rely substantially on public extension services and report using their own production as the primary source of maize consumed. This is a near-ideal combination of characteristics necessary to maximize the adoption-and public health impact-of provitamin A orange maize. 
Table 1: The study design and sample size

\begin{tabular}{|l|c|c|l|}
\hline & \multicolumn{1}{|c|}{$\begin{array}{l}\text { No nutrition } \\
\text { information }\end{array}$} & \multicolumn{2}{|c|}{ Nutrition information through: } \\
\hline & & Simulated Radio & $\begin{array}{l}\text { Community } \\
\text { leaders }\end{array}$ \\
\hline Home-Use Testing & (1) 103 & (2) 89 & (3) 87 \\
\hline Central-Location Testing & (4) 107 & (5) 101 & $X$ \\
\hline
\end{tabular}

Figures in parentheses refer to the treatment number, and those outside refer to the sample size in each treatment arm.

Table 2: Characterizing maize production and consumption characteristics and other summary statistics

\begin{tabular}{|l|c|c|}
\hline & $\begin{array}{c}\text { Home-Use } \\
\text { Testing }\end{array}$ & $\begin{array}{c}\text { Central- } \\
\text { Location } \\
\text { Testing }\end{array}$ \\
\hline Total number of respondents canvassed & 279 & 208 \\
\hline \% reporting maize as primary staple & 100 & 100 \\
\% reporting maize consumption every day & 98 & 100 \\
\% reporting nshima consumption every day & 97 & 100 \\
\hline \% reporting sale of maize & 52 & 76 \\
consumed & 53 & 59 \\
\% reporting purchasing maize for consumption & 62 & 63 \\
\hline \% maize area under hybrids & 57 & 67 \\
\% maize area under modern open pollinated varieties & 11 & 12 \\
\% maize area under local varieties & 32 & 21 \\
\hline \% naming a hybrid as their favorite maize variety & 65 & 73 \\
\% reporting buying improved maize seed once a year & 69 & 52 \\
\hline \% reporting receiving information about maize cultivation & 49 & 55 \\
Of those who received information on maize, & 65 & 16 \\
\% who received information from public extension & 12 & 14 \\
\% who received information from NGOs & 15 & 15 \\
\hline \% who received information from radio & 8 & 71 \\
\% who received information from other sources & 57 & 42 \\
\hline \% reporting ownership of a radio & 25 & 50 \\
Of those who listened to radio, & 72 & 51 \\
\hline \% listening to community radio stations & 38 & \\
\% listening to private radio stations & & \\
\hline
\end{tabular}


Table 3: Summary statistics on selected demographic variables, by treatment

\begin{tabular}{|c|c|c|c|c|c|}
\hline & \multicolumn{3}{|c|}{ Home-Use Testing } & \multicolumn{2}{|c|}{$\begin{array}{l}\text { Central-Location } \\
\text { Testing }\end{array}$} \\
\hline & $\begin{array}{c}\text { No } \\
\text { information } \\
(1)\end{array}$ & $\begin{array}{c}\text { Information } \\
\text { from Radio } \\
\text { (2) }\end{array}$ & $\begin{array}{l}\text { Information } \\
\text { from } \\
\text { Community } \\
\text { Leaders (3) }\end{array}$ & $\begin{array}{c}\text { No } \\
\text { information } \\
(4)\end{array}$ & $\begin{array}{c}\text { Information } \\
\text { from Radio } \\
\text { (5) }\end{array}$ \\
\hline $\begin{array}{l}\text { Sample size (number of } \\
\text { respondents/households) }\end{array}$ & 103 & 89 & 87 & 107 & 101 \\
\hline Average age in years & 48 & 43 & 47 & 42 & 40 \\
\hline $\begin{array}{l}\text { Percent of respondents } \\
\text { with primary education }\end{array}$ & 54 & 60 & 54 & 45 & 45 \\
\hline $\begin{array}{l}\text { Percent reporting farming } \\
\text { as main employment }\end{array}$ & 90 & 98 & 95 & 82 & 80 \\
\hline $\begin{array}{l}\text { Average land cultivated in } \\
\text { hectares }\end{array}$ & 2.2 & 2.3 & 2.0 & 2.9 & 2.8 \\
\hline $\begin{array}{l}\text { Average index of assets } \\
\text { owned }\end{array}$ & 0.2 & 0.3 & 0.3 & 0.4 & 0.3 \\
\hline
\end{tabular}


Table 4: Demographic characteristics of those exhibiting lexicographic preferences

\begin{tabular}{|l|c|c|}
\hline & $\begin{array}{c}\text { Those with lexicographic } \\
\text { preferences (consistently } \\
\text { chose orange across all } \\
\text { choice scenarios) }\end{array}$ & $\begin{array}{c}\text { Those who did not } \\
\text { consistently choose orange } \\
\text { across all choice scenarios }\end{array}$ \\
\hline Age in years & $44.6(15.3)$ & $43.6(15.7)$ \\
\hline Index of assets owned & $0.29(0.19)$ & $0.30(0.18)$ \\
\hline Proportion of males & $\mathbf{0 . 3 3 ( 0 . 4 7 )}$ & $\mathbf{0 . 4 4 ( 0 . 5 0 )}$ \\
\hline Household size & $7.92(3.83)$ & $7.41(4.73)$ \\
\hline Land accessed in hectares & $2.80(2.52)$ & $2.32(2.46)$ \\
\hline
\end{tabular}

Note: Figures in parentheses are standard deviations. Figures in bold are statistically different across the two groups.

Table 5: Log likelihood and Mc Fadden's R-squared values, various models, by treatment arm

\begin{tabular}{|c|c|c|c|c|c|}
\hline & \multicolumn{3}{|c|}{ Home-Use Testing } & \multicolumn{2}{|c|}{ Central-Location Testing } \\
\hline & $\begin{array}{l}\text { No } \\
\text { information } \\
(1)\end{array}$ & $\begin{array}{l}\text { Information } \\
\text { from Radio } \\
(2)\end{array}$ & $\begin{array}{l}\text { Information } \\
\text { from } \\
\text { Community } \\
\text { Leaders (3) }\end{array}$ & $\begin{array}{l}\text { No } \\
\text { information } \\
\text { (4) }\end{array}$ & $\begin{array}{l}\text { Information } \\
\text { from Radio } \\
\text { (5) }\end{array}$ \\
\hline \multicolumn{6}{|l|}{ Log likelihood values } \\
\hline $\begin{array}{ll}\begin{array}{l}\text { Conditional } \\
\text { basic model }\end{array} & \\
\end{array}$ & -1346 & -949 & -1025 & -1477 & -1238 \\
\hline $\begin{array}{l}\text { Random parameters } \\
\text { logit-basic model }\end{array}$ & -1361 & -956 & -1022 & -1513 & -1262 \\
\hline $\begin{array}{l}\text { Conditional logit- } \\
\text { lexicographic model }\end{array}$ & -1184 & -845 & -857 & -1397 & -1066 \\
\hline $\begin{array}{l}\text { Random parameters } \\
\text { logit-lexicographic } \\
\text { model }\end{array}$ & -1202 & -847 & -853 & -1391 & -1091 \\
\hline \multicolumn{6}{|c|}{ Mc Fadden's R-squared } \\
\hline $\begin{array}{ll}\text { Conditional } & \text { logit- } \\
\text { basic model } & \\
\end{array}$ & 0.18 & 0.20 & 0.18 & 0.20 & 0.17 \\
\hline $\begin{array}{l}\text { Random parameters } \\
\text { logit-basic model }\end{array}$ & 0.40 & 0.51 & 0.46 & 0.35 & 0.44 \\
\hline $\begin{array}{l}\text { Conditional logit- } \\
\text { lexicographic model }\end{array}$ & 0.28 & 0.29 & 0.32 & 0.23 & 0.28 \\
\hline $\begin{array}{l}\text { Random parameters } \\
\text { logit-lexicographic } \\
\text { model }\end{array}$ & 0.47 & 0.57 & 0.55 & 0.40 & 0.51 \\
\hline
\end{tabular}


Table 6: Parameter estimates: Random parameter logit model incorporating lexicographic preferences

\begin{tabular}{|c|c|c|c|c|c|}
\hline & \multicolumn{3}{|c|}{ Home-Use Testing } & \multicolumn{2}{|c|}{ Central-Location Testing } \\
\hline & $\begin{array}{l}\text { No } \\
\text { information } \\
\text { (1) }\end{array}$ & $\begin{array}{l}\text { Information } \\
\text { through } \\
\text { radio (2) }\end{array}$ & $\begin{array}{l}\text { Information } \\
\text { from } \\
\text { Community } \\
\text { Leaders (3) }\end{array}$ & $\begin{array}{l}\text { No } \\
\text { information } \\
\text { (4) }\end{array}$ & $\begin{array}{l}\text { Information } \\
\text { from Radio } \\
\text { (5) }\end{array}$ \\
\hline White (ASC) & $6.619(1.24)$ & $6.580(1.58)$ & $5.913(1.36)$ & $4.811(0.63)$ & $0.878(1.25)$ \\
\hline Yellow (ASC) & $4.159(1.26)$ & $2.467(1.81)$ & $2.977(1.36)$ & $3.577(0.64)$ & $3.548(0.93)$ \\
\hline Orange (ASC) & $8.889(1.25)$ & $10.788(1.67)$ & $8.026(1.47)$ & $5.263(0.60)$ & $7.413(0.87)$ \\
\hline Price & -0.003 (neg) & -0.003 (neg) & -0.002 (neg) & -0.004 (neg) & -0.005 (neg) \\
\hline Age*Price & $\begin{array}{c}-0.00005 \\
\text { (neg) }\end{array}$ & $\begin{array}{c}-0.000006 \\
\text { (neg) }\end{array}$ & $\begin{array}{c}-0.00005 \\
\text { (neg) }\end{array}$ & 0.00002 (neg) & 0.00002 (neg) \\
\hline Asset*Price & 0.0003 (neg) & -0.0001 (neg) & -0.0004 (neg) & -0.00001 (neg) & 0.00007 (neg) \\
\hline White*Gender & $0.923(0.70)$ & $-0.725(0.84)$ & $2.063(0.86)$ & $0.438(0.37)$ & $2.036(0.62)$ \\
\hline Yellow*Gender & $0.260(0.70)$ & $0.146(0.87)$ & $1.244(0.86)$ & $0.392(0.38)$ & $-0.128(0.50)$ \\
\hline Orange*Gender & $-0.271(0.69)$ & $-1.711(0.84)$ & $0.728(0.85)$ & $-0.231(0.38)$ & $-0.545(0.49)$ \\
\hline White*Taste & $0.238(0.06)$ & $0.195(0.05)$ & $0.173(0.09)$ & $0.148(0.03)$ & $0.392(0.08)$ \\
\hline Yellow*Taste & $0.420(0.07)$ & $0.324(0.07)$ & $0.417(0.08)$ & $0.220(0.03)$ & $0.375(0.07)$ \\
\hline Orange*Taste & $0.252(0.05)$ & $0.053(0.08)$ & $0.349(0.09)$ & $0.253(0.03)$ & $0.281(0.06)$ \\
\hline
\end{tabular}

Notes: Figures within parentheses are standard errors; "Neg" denotes negligible, extremely small standard errors.

Table 7: Estimated premiums/discounts in willingness to pay for yellow and orange maize relative to white maize, by treatment arm (as percent of willingness to pay for white maize)

\begin{tabular}{|c|c|c|c|c|c|}
\hline & \multicolumn{3}{|c|}{ Home-Use Testing } & \multicolumn{2}{|c|}{ Central-Location Testing } \\
\hline & $\begin{array}{l}\text { No } \\
\text { information } \\
\text { (1) }\end{array}$ & $\begin{array}{l}\text { Information } \\
\text { from Radio } \\
\text { (2) }\end{array}$ & $\begin{array}{l}\text { Information } \\
\text { from } \\
\text { Community } \\
\text { Leaders (3) }\end{array}$ & $\begin{array}{l}\text { No } \\
\text { information } \\
\text { (4) }\end{array}$ & $\begin{array}{l}\text { Information } \\
\text { from Radio } \\
\text { (5) }\end{array}$ \\
\hline \multicolumn{6}{|c|}{ Random parameters logit model with lexicographic preferences } \\
\hline $\begin{array}{l}\text { Orange relative to } \\
\text { white }\end{array}$ & 6 & $17^{* *}$ & $19^{* * *}$ & 8 & $27 * * *$ \\
\hline $\begin{array}{l}\text { Yellow relative to } \\
\text { white }\end{array}$ & $-19 * * *$ & $-21 * *$ & $-19 * * *$ & $-12 * * *$ & $-11^{*}$ \\
\hline \multicolumn{6}{|c|}{ Conditional logit model with lexicographic preferences } \\
\hline $\begin{array}{l}\text { Orange relative to } \\
\text { white }\end{array}$ & 5 & $15^{*}$ & $17^{* *}$ & 7* & $20 * * *$ \\
\hline $\begin{array}{l}\text { Yellow relative to } \\
\text { white }\end{array}$ & $-15^{* *}$ & $-14^{*}$ & $-14^{* *}$ & $-11^{* *}$ & $-11^{*}$ \\
\hline
\end{tabular}

Note: ${ }^{* * *}$ refers to statistical signifcance at $1 \%$ using a one-sided test; ${ }^{*}$ refers to statistical significance at 5 percent using a one-sided test; * refers to statistical significance at the 10 percent level, using a one-sided test. 
Table 8: Estimated willingness to pay per respondent, by maize color, and treatment arm (Zambian kwacha per half-meda)

\begin{tabular}{|c|c|c|c|}
\hline & $\begin{array}{ll}\text { Conditional } & \text { logit } \\
\text { lexicographic } & \end{array}$ & $\begin{array}{l}\text { Random parameters } \\
\text { logit lexicographic }\end{array}$ & $\begin{array}{l}\text { Random parameters } \\
\text { logit all five } \\
\text { treatments } \\
\text { accounting for } \\
\text { endowment effects, } \\
\text { lexicographic }\end{array}$ \\
\hline \multicolumn{4}{|c|}{ Home-Use Testing-No information (1) } \\
\hline White & $2702(131)$ & $2374(115)$ & $2472(93)$ \\
\hline Yellow & 2309 (129) & $1917(116)$ & $2050(93)$ \\
\hline Orange & $2835(133)$ & $2518(116)$ & $2581(93)$ \\
\hline \multicolumn{4}{|c|}{ Home-Use Testing-Information from radio (2) } \\
\hline White & $2750(191)$ & $2435(177)$ & $2375(99)$ \\
\hline Yellow & $2371(187)$ & $1926(192)$ & $2078(98)$ \\
\hline Orange & $3164(196)$ & $2856(178)$ & $2818(100)$ \\
\hline \multicolumn{4}{|c|}{ Home-Use Testing -Information from community leaders (3) } \\
\hline White & $2341(129)$ & $2005(113)$ & $2403(124)$ \\
\hline Yellow & $2010(130)$ & $1624(111)$ & $1904(127)$ \\
\hline Orange & $2730(132)$ & $2380(114)$ & $2790(126)$ \\
\hline \multicolumn{4}{|c|}{ Central- Location Testing-No information (4) } \\
\hline White & $2278(86)$ & $2086(74)$ & $2153(67)$ \\
\hline Yellow & $2033(82)$ & $1830(73)$ & $1882(68)$ \\
\hline Orange & $2443(87)$ & $2256(76)$ & $2272(66)$ \\
\hline \multicolumn{4}{|c|}{ Central-Location Testing-information from radio (5) } \\
\hline White & $2354(111)$ & $1943(103)$ & $2108(81)$ \\
\hline Yellow & 2089 (110) & $1722(94)$ & $1918(82)$ \\
\hline Orange & 2816 (119) & $2483(98)$ & $2583(84)$ \\
\hline
\end{tabular}

Notes: Figures in round parentheses refer to standard errors.

A meda is a common measure of weight in Zambia, and corresponds to 5 kilos. 
Table 9: Accounting for an endowment effect: Parameter estimates of a random parameters logit model, combining all treatment arms, lexicographic preferences

\begin{tabular}{|l|r|}
\hline Variable & \\
\hline White (alternative-specific constant) & $4.671(0.36)$ \\
\hline Yellow (alternative-specific constant) & $4.410(0.37)$ \\
\hline Orange (alternative-specific constant) & $6.137(0.36)$ \\
\hline Price & $-0.003(\mathrm{neg})$ \\
\hline & -0.000004 \\
Age*Price & $(\mathrm{neg})$ \\
\hline Asset*Price & $0.00006(\mathrm{neg})$ \\
\hline White*Gender & $0.093(0.22)$ \\
\hline White*Taste & $0.204(0.02)$ \\
\hline White*HUT & $1.010(0.28)$ \\
\hline White*Radio & $-0.310(0.25)$ \\
\hline White*Community Leaders & $-0.337(0.45)$ \\
\hline Yellow*Gender & $-0.442(0.22)$ \\
\hline Yellow*Taste & $0.248(0.02)$ \\
\hline Yellow*HUT & $0.492(0.29)$ \\
\hline Yellow*Radio & $-0.075(0.26)$ \\
\hline Yellow*Community Leaders & $-0.544(0.46)$ \\
\hline Orange*Gender & $-0.499(0.21)$ \\
\hline Orange*Taste & $0.170(0.02)$ \\
\hline Orange*HUT & $1.115(0.28)$ \\
\hline Orange*Radio & $0.701(0.25)$ \\
\hline Orange*Community Leaders & $0.516(0.45)$ \\
\hline & \\
\hline &
\end{tabular}

Notes:

HUT: Dummy variable taking value one for HUT treatments 1, 2, and 3 Radio: Dummy variable taking value one for radio treatments 2 and 5 Community leader: Dummy variable taking value one for treatment 3 
Figure 1: Districts involved in the study

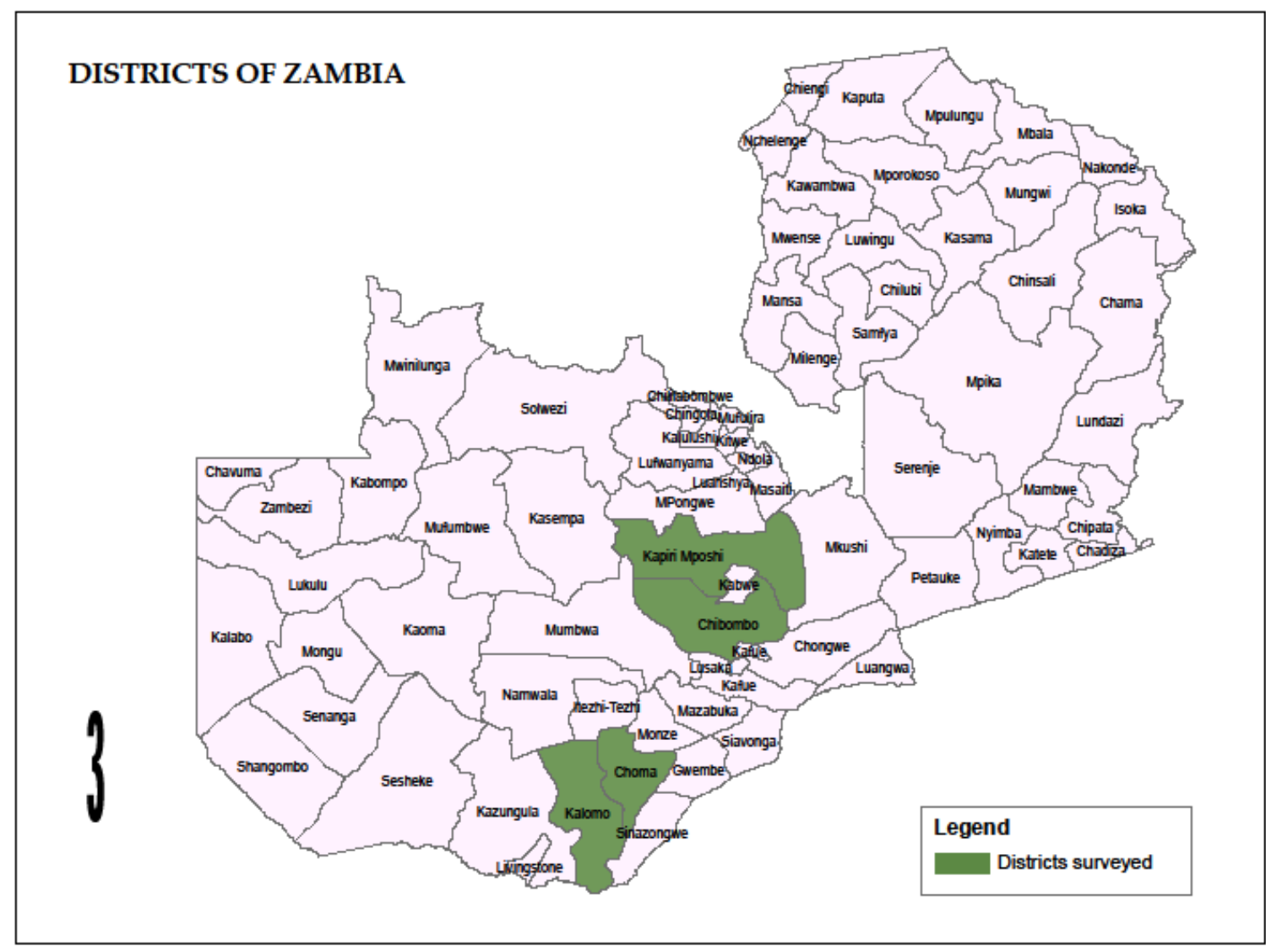


Figure 2: Consumer acceptability scores, by treatment arm

With no
nutrition
information




\section{REFERENCES}

Alfines, F., G. Atle, G. Guttormsen, and K. Kolstad. 2006. Consumers' willingness to pay for the color of salmon: A choice experiment with real economic incentives. American Journal of Agricultural Economics 88(4): 1050-1061.

Robert E Black, Lindsay H Allen, Zulfi qar A Bhutta, Laura E Caulfi eld, Mercedes de Onis, Majid Ezzati, Colin Mathers, Juan Rivera, for the Maternal and Child Undernutrition Study Group. 2008. Maternal and child undernutrition: global and regionalexposures and health consequences. The Lancet, January.

Boutrolle, I., D. Arranz, M. Rogeaux, and J. Delarue. 2005. Comparing central location test and home use test results: Application of a new criterion. Food Quality and Preference 16: 704-713.

Campbell, D., W. George Hutchinson, and R. Scarpa. 2006. Lexicographic preferences in discrete choice experiments: Consequences on individual willingness to pay estimates. Working Paper. Italy: Fondazione Eni Enrico Mattei Note di Lavoro.

Cherry, T. L., S. Kroll, and J. Shogren. 2005. The impact of endowment heterogeneity and origin on public good contributions: Evidence from the lab. Journal of Economic Behavior and Organization 57: 357-365.

Chowdhury, S., J. V. Meenakshi, K. Tomlins, and C. Owori. 2009. Are consumers willing to pay more for biofortified foods? Evidence from a field experiment in Uganda. HarvestPlus Working Paper 3. Washington, D.C.: HavestPlus.

Clark, J. 2002. House money effects in public good experiments. Experimental Economics 5 (3): 223-231.

Das, Sukanya, Rabindra N. Bhattacharya and Ekin Birol, 2009. "Estimating the value of improved wastewater treatment: The case of River Ganga, India," Environmental Economy and Policy Research Working Papers 43.2009, University of Cambridge, Department of Land Economics.

Das, Sukanya, Ekin Birol and Rabindra N. Bhattacharya, 2008. "Informing Efficient and Effective Solid Waste Management to Improve Local Environmental Quality and Public Health: Application of the Choice Experiment Method in West Bengal, India," Environmental Economy and Policy Research Working Papers 33.2008, University of Cambridge, Department of Land Economics.

d'Aspremont, C., J. Gabscewicz and J-F Thisse. 1979. On Hotelling's stability in competition. Econometrica 17: 1145-1151.

De Groote, H., and S. Chege Kimenju.2008. Comparing consumers preferences for color 
and nutritional quality in maize: Application of a semi-double-bound logistic model on urban consumers in Kenya. Food Policy 33: 362-370.

Ferrini, S. and R. Scarpa. 2007. Designs with a priori information for nonmarket valuation with choice experiments: A Monte Carlo study. Journal of Environmental Economics and Management 53(3): 342-63.

Harrison, G. W. 2007. House money effects in public good experiments: Comment. Experimental Economics 10: 429-437.

Hensher, D. A., J. Rose, and W. H. Greene. 2005a. Applied Choice Analysis: A Primer. Cambridge University Press.

Hensher, D. A., J. Rose, and W. H. Greene. 2005b. The implications on willingness to pay of respondents ignoring specific attributes. Transportation 32: 203-22.

Jaeger, S. R. 2005. Non sensory factors in sensory science research. Food Quality and Preference. 17(1-2): 132-44.

Kinnucan, H. W., H. Xiao, C. J. Hsia, and J. D. Jackson. 1997. Effects of health information and generic advertising on US meat demand. American Journal of Agricultural Economics 79(1): 13-23.

Langyuintuo, A., and C. Mungoma. 2008. The effect of household wealth on the adoption of improved maize varieties in Zambia. Food Policy 33: 550-559.

List, J. P. Singha and M. Taylor. 2006. Using choice experiments to value non market goods and services: evidence from field experiments. Advances in Economic Analysis and Policy. 6(2): 1-37.

Louviere, J. J., D. A. Hensher, and J. D. Swait. 2000. Stated choice methods: Analysis and application. Cambridge, England: Cambridge University Press.

Lusk, J. L., and T. C. Schroeder. 2006. Auction bids and shopping choices. Advances in Economic Analysis and Policy 6(1): 1-37.

Lusk, J. L., and T. C. Schroeder. 2004. Are choice experiments incentive compatible? A test with quality differentiated beef steaks. American Journal of Agricultural Economics 86(2): 467-82.

McCann, J. 2005. Maize and grace: Africa's encounter with a new world crop. Cambridge, Mass., U.S.A.: Harvard University Press.

McFadden, D. 1974. Conditional logit analysis of qualitative choice behavior. In Frontiers in Econometrics. ed. P. Zarembka. New York: Academic Press.

Meilgaard, M., G.V. Civile and B.T. Carr. 2007. Sensory Evaluation Techniques. Fourth 
Edition. Florida, USA: CRC Press.

Micronutrient Initiative and others. 2009. Investing in the future: A united call to action on vitamin and mineral deficiencies. Global report. Ottawa, Canada.

Morawetz, U., S. Kimeju, and H. De Groote. 2006. Estimating consumers' willingness to pay for food quality with experimental auctions: The case of yellow vs fortified maize meal in Kenya. Mimeo, CIMMYT.

Muzhingi, T., A. Langyintuo, L. Malaba, and M. Banzinger. 2008. Consumer acceptability of yellow maize products in Zimbabwe. Food Policy 33: 352-361.

Poe, G.L., E.K. Severance-Lossin and M.P. Welsh. 1994. Measuring the difference (X-Y) of simulated distributions: A convolutions approach. American Journal of Agricultural Economics. 76: 904-15.

Scarpa, R and J. Rose. 2008. Design efficiency for non-market valuation with choice modeling: How to measure it, what to report and why. Australian Journal Agricultural and Resource Economics. 52(3): 253-72.

Shaked, A. and J. Sutton. 1982. Relaxing price competition through product differentiation. Review of Economic Studies 49: 3-13.

Stevens, R. and A. Winter-Nelson. 2008. Consumer acceptance of pro-vitamin A biofortified maize in Maputo, Mozambique. Food Policy 33: 341-351.

Taylor, S.D. 2006. Culture and Customs of Zambia. USA: Greenwood Press.

Tschirley, D. L., and A. P. Santos. 1995. Who eats yellow maize? Preliminary results of a survey of consumer maize preferences in Maputo, Mozambique. International Development Working Paper 53. East Lansing, Mich., U.S.A.: Michigan State University.

Train, K. 2009. Discrete Choice Methods with Simulation. Second edition, Cambridge University Press.

Train, K. 1998. Recreation demand models with taste differences over people. Land Economics. 74: 230-39.

Zimicki, S. 1997. Promotion in Sub-Saharan Africa (Part 1). In Net gain: A new method for preventing malaria deaths, ed. C. Lengeler, J. Cattani, and D. de Savigny. Ottawa, Canada: International Development Research Centre. 